\title{
Some cashmere characteristics of hair goats raised in Van province
}

\author{
Selçuk S. Tuncer*
}

\begin{abstract}
The aim of this study was to uncover certain physical properties of cashmere fibres obtained from goat hair in Van, Turkey, and determine their usability in the textile sector. For this purpose 36 hair goats were studied, aged between two and three years old, obtained from breeders at Van Yüzüncü Yıl University Livestock Facilities and the Özalp and Başkale districts of Van, with twelve goats being taken from each breeder. The sample of hairs were collected by combing three areas of the goat's body (shoulder, flank and rump). The analysis indicated that the cashmere length of two-year-old hair goats was longer than that of three-year-old hair goats. There was no linear relationship between the differences among cashmere elasticity and yield properties and the altitude levels of the districts. It was determined that the fibre diameter of the cashmere of hair goats in Van was acceptable for the textile sector and competitive with major cashmere-producing countries.

Key words: cashmere features, hair goat, Van province.
\end{abstract}

\section{INTRODUCTION}

The cashmere produced from goats is a raw material that has been used in the textile industry for centuries; these materials, in turn, constitute raw materials in the fashion industry. These materials can be used in the textile industry either in their pure natural state or mixed with other animal fibres, such as sheep fleece, to achieve the desired physical structure. Although fashion changes and prices in the textile sector have fallen, the value of these fibres remains the same (Leeder et al 1998).

Very few goat breeds in the world benefit from their cover fibres. The hair of the goat consists of two kinds of fibre. The first is the fibre covering the body of the animal, known as guard hair. The second is the fibre called down hair, which protects animals from cold weather in the winter, and is known as cashmere, pashmina, bahare, kork and kaşgora in some regions (Ansari-Renani et al 2013). These fibres, and fibres obtained from other special animals, are called "special and less-produced fibres" in the global textile industry. The fibres in this context include many kinds, including sheep fleece, and can be used to make fabrics and clothes of all quality. Animal fibres impart beauty, softness, colour, texture, brightness, durability and elasticity to the fabric in which they are used (Jensen 1992, Leeder et al 1998, Shakyawar et al 2013). These properties make it possible for cashmere fibres to be a desirable animal fibre in the textile industry.

Caprine breeding provides meat, milk and cashmere production mostly in arid, semiarid and mountainous areas of the world due to the adaptability of the goat to different environmental conditions (Luna et al 2012). Cashmere goats, bred in and around the Tibetan mountains, are a unique breed that has extremely soft down fibres (Ryder

Accepted: 22.06.2018.

Department of Crop and Animal Production, Ozalp Vocational School, University of Van Yuzuncu Yil, Van, Turkey.

*Corresponding author: S Tuncer; selcukseckintuncer@gmail.com and Stephenson 1968). However, it is possible to produce cashmere wool from other breeds rather than this one specific variety. The goats producing the above-mentioned fibre in Europe and Asia are geographically concentrated between $35-55^{\circ}$ north latitude and $50-120^{\circ}$ east longitude. The goat breeds, which are generally known for their down fibre production, adapt to cold regions (Ryder 1993) and are raised in areas at a minimum height of $1000 \mathrm{~m}$ above sea level (Tuncel 1982).

The down fibres are combed, processed and transformed into an important raw material for the textile sector (Ryder and Stephenson 1968). The annual production of cashmere is less than $0.01 \%$ of the world textile market (AnsariRenani et al 2013). China (10,000 tons) and Mongolia (7,400 tons) are the world's largest producers of cashmere and account for 60-70\% of total production. Afghanistan, Iran, Turkey, Kyrgyzstan and other Central Asian countries are the other top cashmere-producing countries (AnsariRenani et al 2013, FAO 2013). Mongolia (6,534 tons) and Afghanistan (1,825 tons) are the most significant exporters of cashmere, while China (8,227 tons) and Italy (1,201 tons) are the most important importing countries (FAO 2013).

The main quality of cashmere is that it is very soft, even softer than wool. It also provides warmth and can be worn for a long time. The average fiber diameter is the main determinant of quality for the textile sector (McGregor 2006, Ansari-Renani et al 2013, Quispe et al 2014). The fibre diameter of processed cashmere must be less than $19 \mu \mathrm{m}$. A value between 16 and $19 \mu \mathrm{m}$ on average is considered appropriate (Jensen 1992). As a matter of fact, the Chinese cashmere is less than $16.5 \mu \mathrm{m}$ and used in luxury tricot as the best fibres. Cashmere with a fibre diameter of more than $16.5 \mu \mathrm{m}$ is generally used in a fabric weave mixed with wool. Fibres with a diameter of $18.5 \mu \mathrm{m}$ are produced in Iran, Afghanistan and Siberia (Ryder 1993).

The goat presence in Turkey approximately doubled from 2009 to 2016, increasing to 10,137,534 heads. Hair goats are the breed raised most commonly (98\%) among goat populations in Turkey (TUIK 2017). 
This study was carried out to investigate the usability of cashmere fibres of hair goats, which are extensively bred in Van, in the textile sector based on certain physical properties.

\section{MATERIAL AND METHODS}

Özalp, Başkale and the Central districts of Van, where the study was carried out, are among the highest altitudes of Turkey with an elevation of 2,075 m, 2,000 $\mathrm{m}$ and 1,727 $\mathrm{m}$, respectively. A total of 36 goats from the three districts were included in the study, with each district providing twelve goats, either two or three years old. The cashmere fibre samples to be analysed were collected, during the months of April and May, with a boxwood comb through the cashmere fibre combing method from three regions of the goat (shoulder, flank and rump).

The final report of this research project was approved by Van Yuzuncu Yil University Animal Research Local Ethic Committee, decision number 2017/02.

Analyses were carried out at Lalahan International Center For Livestock Research and Training. The fleece length was measured in millimeters using the International Wool Textile Organization (IWTO-TM-17-859) analysis method using an USTER AL+FL 100 device. (Albrecht et al 2002, Aytac 2004, Tuncer et al 2017). The fiber diameter (measured in micrometers) was determined using an Optical Fibre Diameter Analyser (OFDA 100). Elasticity (\%) and strength (cN/tex) analyses were tested using Fafegraph Single Fiber Tensile Tester devices. The fiber strength was measured in cN/tex, which is the unit of strength preferred by the textile industry (the weight of $1 \mathrm{~km}$ of thread is approximately $1.0167 \mathrm{~g}$ ) (Tuncer et al 2017).

Analysis of the data was performed using SAS (2014) statistical package program. In the model, the location, the age of the animal and the region where the fibre sample was collected were included as constant environmental factors. The LSMEANS option and the TUKEY test were used to compare the mean values of the groups.

\section{RESULTS}

Results of the cashmere fibre quality by group are shown in Table 1. No statistical differences were found in terms of the quality of cashmere fiber according to body areas of hair goats. Estimated means of fibre length for two-year-old goats $(29.64 \mathrm{~mm})$ were longer than those of three-year-old goats $(25.01 \mathrm{~mm})(P<0.01)$. Cashmere fibre elasticity values were $28.84 \%, 25.63 \%$ and $31.42 \%$ for Özalp, Başkale and the Central districts, respectively. Statistically significant differences $(P<0.01)$ were found between cashmere fibre elasticities of hair goats in all three settlements. The highest fibre elasticity was observed in the goats from the Central region of Van (31.42\%), while the lowest fibre elasticity was determined in the hair goats of the Başkale district (25.63\%). The average hair yield of the Özalp (81.07\%) and Central (81.29\%) districts was lower than the hair yield of the goats from the Baskale region $(84.66 \%)(P<0.01)$.

The correlation between the hair characteristics of the goats is shown in Table 2. Significant relationships were found between fibre diameter and elasticity $(P<0.05)$, fibre diameter and strength $(P<0.01)$, and elasticity and strength $(P<0.01)$.

\section{DISCUSSION}

In this study, the average fibre diameter of two-yearold and three-year-old hair goats was $17.94 \mu \mathrm{m}$ and 17.32 $\mu \mathrm{m}$, respectively. When examining by district, the fibre

Table 1. Various cashmere characteristics of hair goats (mean \pm SEM).

\begin{tabular}{|c|c|c|c|c|c|c|}
\hline & $\mathrm{n}$ & $\begin{array}{l}\text { Diameter } \\
(\mu \mathrm{m})\end{array}$ & $\begin{array}{l}\text { Stample length } \\
\text { (mm) }\end{array}$ & $\begin{array}{c}\text { Elasticity } \\
(\%)\end{array}$ & $\begin{array}{l}\text { Strength } \\
(\mathrm{Cn} / \mathrm{tex})\end{array}$ & $\begin{array}{l}\text { Yield } \\
(\%)\end{array}$ \\
\hline \multicolumn{7}{|l|}{ Age } \\
\hline 2 & 27 & $17.94 \pm 0.38$ & $29.64 \pm 1.52 \mathrm{a}^{* *}$ & $27.74 \pm 1.09$ & $4.56 \pm 0.23$ & $83.10 \pm 1.64$ \\
\hline 3 & 81 & $17.32 \pm 0.16$ & $25.01 \pm 0.63 b^{* *}$ & $29.52 \pm 0.45$ & $4.66 \pm 0.09$ & $82.12 \pm 0.67$ \\
\hline \multicolumn{7}{|l|}{ Districts } \\
\hline Özalp & 12 & $17.76 \pm 0.31$ & $26.23 \pm 1.24$ & $28.84 \pm 0.89 \mathrm{a}^{* *}$ & $4.65 \pm 0.19$ & $81.07 \pm 1.33 \mathrm{a}^{*}$ \\
\hline Başkale & 12 & $17.27 \pm 0.30$ & $27.90 \pm 1.21$ & $25.63 \pm 0.87 b^{* *}$ & $4.35 \pm 0.18$ & $84.66 \pm 1.30 b^{*}$ \\
\hline Center & 12 & $17.86 \pm 0.26$ & $27.85 \pm 1.03$ & $31.42 \pm 0.73 \mathrm{c}^{* *}$ & $4.83 \pm 0.15$ & $81.29 \pm 1.10 \mathrm{a}^{*}$ \\
\hline \multicolumn{7}{|l|}{ Areas } \\
\hline Shoulder & 36 & $17.81 \pm 0.33$ & $28.48 \pm 1.34$ & $22.77 \pm 0.96$ & $4.45 \pm 0.20$ & $84.27 \pm 1.44$ \\
\hline Flank & 36 & $17.49 \pm 0.36$ & $27.11 \pm 1.45$ & $28.93 \pm 1.04$ & $4.74 \pm 0.22$ & $80.74 \pm 1.56$ \\
\hline Rump & 36 & $17.59 \pm 0.33$ & $26.39 \pm 1.34$ & $29.19 \pm 0.96$ & $4.64 \pm 0.20$ & $82.81 \pm 1.44$ \\
\hline
\end{tabular}

SEM: standard error of the mean.

a, b: Different lower cases in the same column represent statistically significant differences $\left({ }^{*}: P<0.05,{ }^{* *}: P<0.01\right)$. 
Table 2. The correlations among the hair characteristics of the hair goats $(n=108)$.

\begin{tabular}{lccccc}
\hline & Diameter & Stample length & Elasticity & Strength & Yield \\
\hline Diameter & 1 & 0.23 & $0.28^{*}$ & $0.49^{* *}$ & 0.10 \\
Stample length & & 1 & 0.18 & 0.18 & -0.01 \\
Elasticity & & 1 & $0.61^{* *}$ & -0.11 & 0.02 \\
Strength & & & 1 & 1 \\
Yield & & & &
\end{tabular}

diameters of hair goats bred in Özalp, Başkale and the Central districts were $17.76 \mu \mathrm{m}, 17.27 \mu \mathrm{m}$ and $17.86 \mu \mathrm{m}$, respectively. Evaluating by area of the body where samples were obtained, the fibre diameters were determined to be $17.81 \mu \mathrm{m}, 17.49 \mu \mathrm{m}$ and $17.59 \mu \mathrm{m}$ at shoulder, flank and rump, respectively. The results revealed that the cashmere fibre diameters of hair goats in this study were thicker than those of British milk goats $(<14 \mu \mathrm{m})$ (Ryder 1993), Kilis goats (16.2 $\mu \mathrm{m})$ (Kaymakçı and Aşkın 1997), hair goats in Turkey $(16 \mu \mathrm{m})$ (Eliçin et al 2000) and (16.6 $\mu \mathrm{m})$ (Gökmen and Boztepe 2004), and South African domestic goats (14.0-16.5 $\mu \mathrm{m})$ (Braun and Roux 2005); they were also found to be most similar to South African Boer goats (16.0-18.5 $\mu \mathrm{m})$ and Savannah goats (16.0-18.5 $\mu \mathrm{m})$ (Braun and Roux 2005). These values were higher than hair goat cashmere reported by Bolat (2006) (14.3 $\mu \mathrm{m})$ and Chinese cashmere reported by Mengüç and Özdil (2014) (14.5$15.5 \mu \mathrm{m})$, most similar to Mongolian cashmere (16.5-17.5 $\mu \mathrm{m})$, and finer than Gorno Altai (18.5-19.0 $\mu \mathrm{m})$ (Braun and Roux 2005), Turkish hair goats $(18.2 \mu \mathrm{m})$ (Kuloğlu 2010), Iranian and Afghanistan goat cashmeres (17-18.5 $\mu \mathrm{m})$ (Mengüç and Özdil 2014).

The cashmere fibre lengths of two-year-old and three-year-old hair goats were $29.64 \mathrm{~mm}$ and $25.01 \mathrm{~mm}$, respectively, while the fibre lengths of goats bred in Özalp, Başkale and Central were $26.23 \mathrm{~mm}, 27.90 \mathrm{~mm}$ and 27.85 $\mathrm{mm}$, respectively. The cashmere lengths of samples obtained from the shoulder, flank and rump were $28.48 \mathrm{~mm}, 27.11$ $\mathrm{mm}$ and $26.39 \mathrm{~mm}$, respectively. It was observed that the cashmere lengths of two-year-old goats were significantly longer than those of three-year-old goats $(P<0.01)$. This result can be explained by the negative effects of environmental conditions on the cashmere length, which have increased over the years. These length values were found to be similar to those of Turkish hair goats reported by Eliçin et al (2000) (28 mm), South African Boer (20-31 $\mathrm{mm})$, and Savannah goats $(20-31 \mathrm{~mm})$ reported by Braun and Roux (2005). On the other hand, the cashmere length values obtained from the study were lower than those of Kilis goats (53 mm) (Kaymakçı and Aşkın 1997), Chinese cashmere (48.9 mm) (McGregor (2002), Gorno Altai goat cashmere (28-45 mm) (Braun and Roux 2005), cashmere of hair goats in Turkey (44 mm) (Bolat 2006), Krygyzstan cashmere (50 mm) (FAO 2009) and cashmere of hair goats (38.01 mm) (Kuloğlu 2010). The values were also higher than the cashmere of South African domestic goats (15-30 $\mathrm{mm}$ ) (Braun and Roux 2005).

When considering age groups, cashmere fibre elasticities of the two-year-old and three-year-old hair goats were found to be $27.74 \%$ and $29.52 \%$, respectively. In terms of districts, cashmere elasticities of hair goats in Özalp, Başkale and the Central regions were 28.84\%, 25.63\% and $31.42 \%$, respectively. When examining body areas from which samples were obtained, elasticity values were found to be $27.77 \%, 28.93 \%$ and $29.19 \%$ at the shoulder, flank and rump, respectively. Significant differences were observed among elasticity ratios at the district level $(P<0.01)$, with the highest elasticity ratio being observed in the Central district and the lowest in the Başkale goat population. The results of the research indicated that elasticity ratios were lower than hair goat down fibre cashmeres (33\%) (Gökmen and Boztepe 2004), Australian cashmeres (50\%) and other important cashmere-producing countries. (38.8\%) (McGregor and Postle 2004).

Cashmere fibre strength was found to be $4.56 \mathrm{Cn} /$ tex and $4.66 \mathrm{Cn} /$ tex for two-year-old and three-year-old hair goats, respectively. Cashmere fibre strengths of hair goats bred in Özalp, Başkale and the Central districts were 4.65 Cn/tex, 4.35 Cn/tex and 4.83 Cn/tex, respectively. Cashmere fibre strengths of the samples obtained from the shoulder, flank and rump were $4.45 \mathrm{Cn} / \mathrm{tex}, 4.74 \mathrm{Cn} /$ tex and $4.64 \mathrm{Cn} /$ tex, respectively. These values obtained from the research were lower than Australian cashmeres (11.2 Cn/tex) and other important cashmere producers (10.3 Cn/tex) (McGregor and Postle 2004), while higher than Turkish hair goat cashmere fibres $(2.5 \mathrm{Cn} /$ tex $)$ reported by Gökmen and Boztepe (2004).

Examining by age group, cashmere yields were found to be $83.10 \%$ and $82.12 \%$ for two-year-old and threeyear-old hair goats, respectively. Cashmere yields of hair goats bred in Özalp, Başkale and the Central districts were determined to be $81.07 \%, 84.66 \%$ and $81.29 \%$, respectively. When evaluating the cashmere yields of body regions from which samples were obtained, they were $84.27 \%, 80.74 \%$ and $82.81 \%$ for the shoulder, flank and rump, respectively. Significantly higher $(P<0.01)$ cashmere 
yields of hair goats bred in the Başkale district can be explained by better sheltering conditions for the goats at this location. These values were found to be lower than average cashmere yield ratios for Turkish hair goat $(87 \%)$ reported by Gökmen and Boztepe (2004), while they were significantly higher than those for South African Boer goats (50-70\%), Savannah goats (50-70\%), conventional domestic goat cashmere (40-60\%) and the cashmere of Gorno Altai goats (50-70\%) reported by Braun and Roux (2005). The reason for high cashmere yield ratios obtained in this study may be that the method for determining the cashmere yield ratio was different. In this research, guard hairs were combed out before yield analysis, but in some studies, some guard hairs were considered to be fibre cashmere contaminants and wastage, which decreased the yield ratio (Wang et al 2008).

It can be concluded that cashmere fibre length significantly decreases with age. Further studies will be useful for determining the impact of environmental conditions to better identify the age effect on cashmere fibre length. There were no significant differences among the districts in this research, except for elasticity and yield of the cashmere quality characteristics. There was no parallel relationship between these significant differences in elasticity and yield properties and the altitude levels of districts. While the fibre diameters of the hair goat cashmere, which is the most important quality parameter in the textile, were within acceptable values for the textile industry, the cashmere fibre lengths were not found to be a sufficient length. Moreover, while the elasticity and strength values were lower than the major cashmere-producing countries in the world, the cashmere yield ratios were higher.

\section{ACKNOWLEDGEMENTS}

This study was supported by Research Fund of the Van Yuzuncu Yil University. Project number FBA-2017-5110.

\section{REFERENCES}

Albrecht W, Fuchs H, Kittelmann W. 2002. Nonwoven Fabrics: Raw Materials, Manufacture, Applications, Characteristics, Testing Processes. Wiley-VCH, Weinheim, Germany.

Ansari-Renani HR, Rischkowsky B, Mueller JP, Moradi S. 2013. Cashmire in Iran. Animal Sciences Research Institute, Karaj, Iran.

Aytac M. 2004. Production characteristics in White Karaman, Sakız x White Karaman F1 and G1 and Kivırcık x White Karaman F1 and G1. PhD Dissertation, Ankara University, Ankara, Turkey.

Bolat Ü. 2006. Cashmere production potential and physical characteristics of hair goats raised in Adana Region and its application in textile sector. MSc Dissertation, Çukurova University, Adana, Turkey.
Braun AL, Roux JA. 2005. Progress in the utilization and promotion of South African indigenous goats for cashmere production. $8^{\text {th }}$ International Goat Congress in Pretoria, Pretoria, South Africa.

Eliçin A, Dellal G, Söylemezoğlu F, Erdoğan Z, Arık İZ. 2000. Some physical characteristics and using areas of corse and down fibres in hair goat. Ankara University Press, Ankara, Turkey.

FAO, Food and Agriculture Organization of the United Nations. 2009. Part 1: Wool and cashmere. Food and Agriculture Organization of the United Nations, Rome, Italy.

FAO, Food and Agriculture Organization of the United Nations. 2013. Crops and livestock products. Food and Agriculture Organization of the United Nations.

Gökmen M, Boztepe S. 2004. Determination of cashmere fiber production and quality traits in Turkish hair goat. J Anim Vet Adv 3, 781-784.

Jensen HL. 1992. Cashmere production in the United States. Leafy Spurge Symposium and Proceedings, July 22-24, Lincoln, NE, USA, Pp 7-9.

Kaymakçı M, Aşkın Y. 1997. Goat Breeding. Baran Ofset Press, Ankara.

Kuloğlu BH. 2010. Some physical properties of coarse and down fibres obtained from hair goat kids. MSc Dissertation. Ankara University, Ankara, Turkey.

Leeder JD, Mcgreoger BA, Steadman RG. 1998. Proporties and performance of goat fibre a review and interpretion of existing research results. Rural Industries Research and Development Corporation. RIRDC Pub. No: 98/22. RIRDC Project No: ULA 8A, Victoria, Australia.

Luna A, Hernandez S, Sanchez M, Lopez R, Medina L, et al. 2012. Microsatellite loci and paternity analysis in Nubia and Boer goats. Arch Med Vet 44, 123-127.

McGregor BA. 2002. Australian Cashmere - attributes and processing. Rural Industries Research and Development Corporation. Pub. $N^{\circ} 02 / 112$, Barton ACT, Australia.

McGregor BA. 2006. Production, attributes and relative value of alpaca fleeces in southern Australia and implications for industry development. Small Rumin Res 61, 93-111.

McGregor BA, Postle R. 2004. Processing and quality of cashmere tops for ultra-fine wool worsted blend fabrics. Int J Cloth Sci Tech $16,119-131$.

Mengüç GS, Özdil N. 2014. Specialty Animal Fibers. Electronic Journal of Textile Technologies 8, 30-47.

Quispe EC, Poma AG, McGregor BA, Bartolome J. 2014. Effect of genotype and sex on fiber growth rate of alpacas for their first year of fleece production. Arch Med Vet 46, 151-155.

Ryder ME, Stephenson SK. 1968. Wool And Growth. Academic Press, London, UK.

Ryder M. 1993. The use of goat hair an introductory historical review. Anthropozoologica 17, 37-46.

SAS, Statistical Analysis System. 2014. SAS version 9.4. SAS Institute Inc., Cary, NC, USA.

Shakyawar DB, Raja ASM, Kumar A, Pareek PK, Wani SA. 2013. Pashmina fibre-production, characteristics and utilization. Indian J Fibre Text 38, 207-214.

TUIK, Turkish Statistical Institute. 2017. Livestock Statistics. Istanbul, Turkey.

Tuncel E. 1982. The relationships among some hair characteristics, hair yield and body weight and measures in the Kilis Goats. Pub. $N^{o} 831$, Ankara University, Ankara, Turkey.

Tuncer SS, Sireli HD, Dellal G. 2017. Comparative analysis of various fleece characteristics of Norduz and Zom sheep. J Anim Plant Sci 27, 763-770.

Wang L, Singh A, Wang X. 2008. A Study on Dehairing Australian Greasy Cashmere. Fiber Polym 9, 509-514. 